\title{
Mujer y violencia en El Salvador
}

\author{
Zoila de Innocenti, Carolina Quinteros \\ Nidia Umana, Alvaro Artiga
}

El presente artículo es un resumen de una investigación hecha por el departamenlo de Sociologla y Ciencias Políticas de la Universidad CenIroamericana "José Simeón Caf́as" en colaboración con la Organización Panamericana de la Salud (OPS) sobre la problemática "Mujer y Violencia en El Salvador" con énlasis en las áreas legal y de salud, realizada entre los meses de Diciembre de 1991 y Enero de 1992. El departamento decidió hacer este resumen y publicarlo en esta revista para contribuir a romper el silencio respecto de un problema al cual todas las mujeres están en riesgo de verse involucradas como víctimas y que, por lo tanto, forma parte de la realidad social del pais pero que suele pasar desapercibido porque muchas veces ocurre en el llamado ámbito doméstico.

La invesligación lue más de carácter cualitativo que cuanlilativo, en parte por el corto periodo para su realización. Además se insistió en la elaboración de un marco teórico inlerprelativo que permitiera tener una amplia visión acerca del problema. La parte que abordó la siluación concrela en El Salvador se centró en el estudio de las instituciones u organismos, gubernamentales o no gubernamentales, que atienden a las víctimas estableciendo el lipo de violencia, la atención que ofrecen y las dificultades que encuentran. De esa forma se formularon una serie de conclusiones y recomendaciones.

\section{MARCO CONCEPTUAL GENERAL.}

Por violencia generalmente se entiende el uso excesivo de la fuerza 
contra una o varias personas, animales o cosas. El problema con esta definición es que permile considerar sinónimos a la violencia y la agresión, siendo que no coinciden tolalmente.

Si se acepta que el concepto más amplio es el de violencia, la agresión serla un tipo especial de violencia; aquel en que va expresa o implicitamente la intención del actor de causar dafio al otro (MartínBaró, 1988). Una consecuencia importanle de esta distinción es que permite mantener deniro del concepto de violencia aclos y situaciones que tendrlan que quedar luera si la violencia se redujera a simple agresión. Asi la violencia conlra la mujer no es solamente la agresión contra la mujer tal como más adelante se planteará. Es más, asi se puede hablar de situaciones violentas all donde quienes delentan poder sobre otros han extendido un "manto ideológico" para ocullar su carácler violento o simplemente donde lo que ellos hacen ni siquiera lo consideran violenlo. Esto sucede no solo entre grupos sociales contrarios sino en las mismas relaciones entre hombres y mujeres, es decir, en las relaciones entre géneros.

Aqui se adoplará la siguiente definición de violencia: el uso de la luerza en una relación desigual y al servicio del poder para obligar a una persona a vivir o experimentar una situación que no consentiria libremente y que amenaza, arriesga o destruye su integridad física, emocional o social. Aquella fuerza puede ser lísica o psicológica, directa o indirecta; a través de ritos, símbolos, tradiciones, leyes, educación, el imaginario popular o el inconsciente colectivo (Facio,1989; Fran$c 0,1991)$. Como se ve, la definicion de violencia que aqul se planlea evila la reducción de ésta a meros actos violentos. La violencia implica una situación, un estado de cosas; los actos y conductas violentas no suelen ser esporádicos. Una siluación violenla se manifiesta precisamente en actos y conduclas violentas.

\subsection{El aprendizaje de la vlolencla.}

Una sociedad violenta en su origen mismo propicia, exige y justitica la realización de actos violentos, el establecimienlo, conservación y reproducción de relaciones autoritarias y jerárquicas, para garantizar su "ordenado" funcionamienlo y supervivencia en el tiempo. Los miembros de esa sociedad aprenden del entorno las conductas violentas y las justilicaciones que se dan de la violencia. Aprenden que algunos tipos de violencia son aceplables y permitidos y que quien usa la violencia puede resolver sus problemas, obtener to que quiere y controlar a otros (Martin-Baró, 1988). 
Ahora bien, como la violencia no se reduce a actos, también se aprende a defender la matriz de la violencia, es decir la situación que posibilita comportarse violentamente. Este hecho resulta de gravedad puesto que el aprendizaje social de la violencia, en especial el que tiene lugar en la familia, no es igual para lodos los miembros de la sociedad.En una sociedad patriarcal, mientras los hombres adquieren y ejercen poder por su posición superior ligada con aclividades realizadas en el ámbito social, crecen fuertes y rudos, aprendiendo a mostrar su "hombria" a través de la fuerza física, el dominio y el conirol de sus emociones. Asl habria que pregunlarse si en los mismos procesos de adquisición de la personalidad así como del rol sexual ¿no estaria ya una semilla violenta que germinará posteriormente si "la tierra donde cae es propicia", si la sociedad donde vive es ya violenla en su estructuración?. Por otra parte, en este drama de aprendizaje social de la violencia, las mujeres quedan limiladas al ámbilo doméstico, como prolongación de la propiedad privada de quien ejerce el poder. Ellas han asumido como atribulos propios la debilidad y la sumisión, una actitud sacrificada y dependiente del hombre. El hombre entonces no sólo se cree con derecho a controlar a las mujeres y a los nif́os, sino que cree tener acceso al uso "legítimo" de la violencia.

Finalmente, en la medida en que continúa posibilitándose el ejercicio de la violencia mediante un contexto que la permita y la juslifica se está haciendo posible una conslante recreación de esa siluación en forma creciente. Se está estableciendo una espiral de la violencia que explica la dinámica multiplicadora de los actos violentos.

\subsection{Tipos de violencla.}

Puede hacerse una clasilicación de la violencia de acuerdo al lugar donde se manifiesta. En este sentido se hablará de violencia en el ámbilo social y de violencia en el ámbito doméstico (analogamente a la división que se hace entre trabajo social y trabajo doméslico).

Se opta por los términos "ámbito social" y "ámbilo doméslico" como jenominación allernativa a "pública" y "privada" respectivamente porque éstos alirman la distinción-separación de espacios que colocan en desventaja a las mujeres cuando recurren a las instancias pertinentes en busca de asistencia, prolección, justicia, etc. Sobre la violencia en el "ámbito privado" ni siquiera se cree que vale la pena hablar porque sería una cueslión familiar que debe Iratarse y resolverse sin injerencia externa. Además, al hablar de "ámbito social" y "ámbilo doméstico" no se oculta el carácter público de todo tipo de violencia y se posibilita pensar en medidas de orden público (que afeclan a la población) para combatir 
la violencia independientemente del ámbito en donde aconlezca.

\subsection{Vlolencia en el ámblto soclal.}

Esta es la violencia que se da fuera del hogar, entendido éste en un doble sentido: como espacio lísico y como espacio familiar. Según el tema de esta exposición debe hacerse una distinción necesaria: hay violencia no sexista (por ejemplo: bélica, socio-económica, juridica, polilica, ideológica-religiosa, elc.), es decir que no va dirigida ni a hombres ni a mujeres por razón de su sexo pero que atecta mayormente a las mujeres. $Y$ hay violencia que podría llamarse genérica cuya víclima directa es la mujer. Esta distinción intenta responder al viejo problema de la opresión de que es víctima la mujer en tanto miembro de un grupo o clase social y la dominación que sufre en tanto género. En esle resumen se hace referencia unicamente a la violencia contra la mujer y se trata de lodas aquellas áreas de la vida social en donde se violenta a la mujer por razón de su sexo.

Hay violencia en los procesos de socialización secundaria cuando desde el grupo de amigos, la escuela, la religión, los medios de comunicación, se le enseña a la mujer a considerarse como persona no capaz para ciertas tareas, insegura y por lo mismo dependienle de otro para la toma de responsabilidades. Sin más recurso que su cuerpo, la familia le espera como su puerto y su cárcel (Martín-Baró, 1988).

La sociedad la considera así, ella misma se considera de esa manera en muchos casos. Esta siluación además de lo denigrante es un factor que se podría considerar incluso como causa de que las mujeres muy pocas veces tengan acceso a recursos productivos necesarios para la manutención familiar. Específicamente la consideración de la mujer como ama de casa ha sido planteada como una de las razones que explican el que las reformas agrarias en América Latina no han dado acceso a las mujeres al recurso tierra.

Hay también violencia en el trabajo y se presenta en aquellos casos en que a las mujeres no les queda otra alternativa que trabajar en doble y a veces hasla en triple jornada de trabajo, ya que además del trabajo productivo (que genera ingresos o productos para la subsistencia de la familia y que pasa por el mercado), realiza el (rabajo doméstico reproductivo. Cuando se le niega el acceso a los medios de producción, a los bienes y servicios sociales, cuando hay una discriminación con respecto a cuál trabajo puede realizar y qué salario debe recibir. Cuando sufre el asedio sexual por parte de sus companeros y superiores (hombres) o de los usuarios o clientes. 
Hay violencia en la calle y se evidencia cuando en la calle misma, en los autobuses, en los lugares de recreación, los hombres las manosean, les exhiben sus genitales, hacen gestos o usan palabras obscenas para referirse al cuerpo de la mujer. Esto tiene especial Impacto para la mujer ya que desde nifias han sido educadas para entrentarse a su cuerpo y al de los hombres de manera diferente: las nifas deben ser recaladas y pudorosas, no asl los ninos.

Incluso hay violencia en la salud por ejemplo, cuando los programas existentes conciben y atienden a la mujer sólo como madre, sin considerar sus requerimientos de salud en otras áreas de su vida. Cuando los mélodos de planificación familiar son destinados en su mayoria al cuerpo de la mujer, cuando se practican cesáreas forzadas y cuando se imponen eslerilizaciones; y en general cuando las relaciones médicopaciente durante los examenes y el parto responden más a la comodidad del médico que a las necesidades de la mujer.

Hay violencia en las leyes cuando se dictan o simplemente se mantienen leyes que favorecen a los hombres y discriminan a las mujeres.

Se considera como violencia sexual cuando se abusa sexualmente de las mujeres, se explota su cuerpo a través de la prostitución y se Irafica con ellas.

$Y$ hay violencia en el lenguaje cuando a las mujeres se les ignora en éste y se les hace aparecer como si ellas fueran incluidas en algunos términos expresados en forma androcéntrica. Por ejemplo, los documenlos para trámites legales tienen términos formulados en forma androcénlrica: ciudadano, propietario, licenciado, etc.

\subsubsection{Vlolencla domésllca.}

Esle es el lipo de violencia del cual no se quiere hablar porque se nos ha ensefiado que "no se debe hablar mal de su casa" y porque "pondremos en mal a un ser querido". El oásis que deberia ser el hogar, el lugar de reposo y tranquilidad, el lugar de "leche y miel" suele convertirse para muchas mujeres en el lugar donde diariamente mueren y donde "los companeros de vida más bien son liranos de muerte" (Cahas, 1989) y donde las victimas suelen ser también los nifos y ninas. En este ámbito las amenazas o golpes por parte de sus companeros se ven como naturales.

Las manilestaciones de la violencia doméstica pueden clasificarse en cuatro tipos (ibid): 
- Socialización primaria, cuando desde pequenas, las mujeres son educadas para el hogar, el matrimonio y la familia, exclusivamente; limitándoles una experiencia más amplia del mundo al que como seres humanos lienen derecho. Cuando solamente tienen acceso a un delerminado tipo de juegos y de juguetes que no les permilen desarrollar habilidades diferentes a las de sus roles tradicionales.

- Abuso emocional y psicológico: burlas, insultos, gritos, ridiculización; cuando nunca o casi nunca se le acaricia y se molesla cuando la mujer es carifiosa; cuando se culpabiliza a la mujer de todos los problemas de la familia; cuando se le acusa de loca, eslúpida, vieja, histérica, puta, etc. Cuando se le critica como madre, amanle y trabajadora; cuando se le exije alención en todo momento, incluso llega a competir con sus propios hijos; se les responsabiliza de casi todos los problemas de la familia, se les amenaza con golpes a ellas o a los hijos, se les humilla con cuentos de aventuras de los hombres con otras mujeres (que muchas veces no son solo cuentos), etc.

- Abuso físico, es la agresión directa por parte de los esposos o companeros que va desde los pellizcos, las botetadas, los empujones, apretones, los cinchazos, las paladas, las heridas, los golpes en partes específicas del cuerpo, las quebraduras de huesos, la agresión con armas, pistolas, cuchillos, veneno y hasla el homicidio.

- Abuso sexual, cuando se les asedia sexualmente en momentos inoportunos o se las fuerza a tener relaciones en contra de la voluntad de ellas. Cuando se burla de su cuerpo y de la forma en que hace el amor, cuando se le acusa de infidelidad, se las ignora, se les niega las necesidades de ellas y sus sentimientos, se les maltrata durante el acto sexual o se les obliga a tener relaciones sexuales después de golpearla, etc.

\subsection{Mitos y Factores que contribuyen a la vlolencla.}

El que tanlo las conduclas violentas y su justificación sean en gran medida fruto de un aprendizaje social nos permile entender mejor algunas explicaciones dadas y sefalar algunos factores que contribuyen a la violencia y la manera cómo afectan a la familia, la sociedad y al estado.

\subsubsection{Mitos.}

Con frecuencia las explicaciones dadas al por qué de la violencia son elaboradas desde la perspectiva de quienes detentan el poder para justificar la siluación violenta y los actos en que ésta se manifiesla. Por lo tanlo, al reducir la violencia al acto violento, dichas explicaciones resul- 
tan ser falsas o insuficientes para dar cuemta de las causas de la violencia y para considerar el punlo de vista de las victimas.

En el caso de la violencia que liene como victima a las mujeres se dice que es el resultado del uso o abuso de drogas, cuando no todas las mujeres ni siempre han sido agredidas por un hombre que al no estar en pleno control de sus capacidades no se diera cuenta de sus actos ni del dano ocasionado.

También se dice que el tácil recurso a la violencia por parte de los nombres se debe a que no pueden expresar sus sentimientos o manejar de otra manera las presiones colidianas a que están somelidos. Asl la violencia serla un rellejo de la insatisfacción de las necesidades básicas, de los problemas de desempleo, de carencia de vivienda y salud que se vive en nuestra sociedad. Si se considera que la realización de tareas reproductivas, multiplica las tareas y las combina con tareas productivas exigiendo conslanles cambios de rol con el consecuente desgasle físico y emocional, las mujeres se encuentran somelidas a iguales o mayores presiones y no necesariamente reaccionan ulilizando la violencia. Además no todos los hombres que agreden a las mujeres se encuentran atravesando graves dilicullades emocionales.

También se dice que depende del estrato social al que pertenece la familia y del nivel educativo del hombre, aunque no es dificil encontrar similares actitudes violenlas en obreros y patronos, en analiabetos y profesionales, en albaniles y psicologos. Se ha llegado a decir que la violencia que afecla a las mujeres es una sefial de alecto por parte de los hombres, interesados en cumplir con el derecho y la responsabilidad de controlar a la mujer, que la sociedad les ha asignado.

Se argumenta olras veces que la mujer es la responsable de la violencia porque "se la busca" con su conducla provocaliva o con su conducta irresponsable al no alender las necesidades sexuales del hombre o las necesidades de cuidado de su familia.

Aunque los aclos de agresión sexual conira las mujeres y sus hijos(as) no son explicables unicamenle como un deseo erótico sexual no satislecho o estimulado por la mujer misma. Estas explicaciones no sólo evaden y ocultan las causas de la violencia conlra las mujeres, sino que distorcionan los actos mismos y la posición de las personas involucradas. Se hacen aparecer como acciones realizadas por un hombre sin control de sí mismo que resulla ser la victima de sus instintos, del uso de drogas, de los medios de comunicación o incluso víctima de la conducta misma de las mujeres. 


\subsubsection{Factores.}

Para superar en alguna medida las explicaciones senaladas y que han sido conslderadas falsas o insuriclentes es necesario recordar que existe una situación violentá que se manifiesta en actos particulares y concrelos. Los factores que contribuyen a la violencia pueden ser idenlificados como relativos a un contexto que la hace posible y a un transfondo ideológico que la permite, reproduce y justifica.

La división del trabajo entre hombres y mujeres, realizando tareas propias de la reproducción biologica, social y material unas y tareas productivas en el ámbito social los otros, explica la existencia de un acceso desigual a los recursos para la participación en la toma de decisiones y para garantizar la vida. La aceplación de estas dilerencias es una aceptación de la discriminación como principio ordenador de las relaciones entre los grupos y entre las personas.

En esle contexto marcado por las desigualdades y por las relaciones jerárquicas, autoritarias y de carácler subordinado enlre hombres y mujeres, la violencia es una forma de ejercer el poder por parte de los hombres para mantener el orden y el control sobre los recursos y sobre las mujeres y los nifos. Pero la violencia no siempre puede ni necesariamente debe ser utilizada abiertamente. Existen una serie de valores, normas y prácticas que no sólo favorecen su uso, sino que lo justifican y transmilen. Con esto se garantiza tanto su aceplación por parte de la sociedad en general, y de las mujeres en particular, como su reproducción y permanencia.

AsI la violencia que tiene como victima a la mujer se va institucionalizando al ser un elemenlo presenle en $i$ " legislación y en inslituciones sociales como la familia y la escuela.

Esle conlexto social amplio que configura unos actores, objetos y simbolos particulares hace posible que la violencia conira la mujer surja en las más diversas siluaciones y relaciones sociales. Dicha violencia se hace posible cuando se encuentran tres elementos importantes: un agente que al gozar de cierta cuola de poder en relación con la víctima tiene derecho a controlarla o somelerla mediante el uso de la fuerza. Aún más si su uso es la conducta esperada del grupo social al que pertenece y se traducirá en un aumento de su presligio y status social como tal. Una victima que tiene un bajo slatus social, que es considerada menos que un ser humano (al ser tomado como criterio de lo humano quien controla el poder) o sencillamente diterente de la condición y dignidad del agresor. Esta posición social subvalorada de la mujer la hace vulnerable a ser discriminada en los aspeclos laboral, legal, social, 
político, cientifico, etc. $Y$ vulnerable también para ser victima de la violencia en tanto que es considerada un ser humano de segunda categoría que debe y puede ser conlrolada por los hombres. $Y$, finalmente, un escenario que estimula la ejecución de actos violentos.

Pueden relomarse ahora algunas de las explicaciones dadas al por qué de la violencia contra la mujer y que aisladas y absolutizadas resullan falsas o insuficientes, pero que en el contexto social amplio de una siluación violenla que afecta a la mujer en forma directa o Indirecta resullan importantes para el análisis y la explicación. Deben ser tomados en cuenta como elementos agravantes (no causantes) que imprimen un sello particular a las manifestaciones de la vlolencia en actos concretos, especificos y determinados. Algunos de dichos elementos agravantes son: el uso de drogas y alcohol, la movilidad limitada de la mujer, la presión que el grupo ejerce sobre el hombre, tensiones de la vida cotidiana, las dificultades encontradas para garantizar la sobrevivencia, el nivel educativo, el grupo social al que se pertenece, el pasado de la mujer, el haber crecido en un hogar violento, la pornografía, el impaclo de los medios de comunicación, entre otros.

\subsection{Efectos.}

La violencia que tiene a la mujer como victima es un aspecto de la situación establecida a nivel social. Afecta directa o indirectamente a la mujer en mulliples formas; y a la sociedad en su conjunto lanto al realizarse como al ignorarse.

Los actos violentos que lienen a la mujer como víctima afectan a la familia. Las mujeres victimas de la violencia poseen un bajo nivel de autoestima y viven en el miedo, la vergūenza y la culpa por lo que les sucede. Les lleva a asumir actiludes de condescendencia, de sacrificio o de aislamiento para conservar la unidad de la familia. Los ninos al ser "testigos presenciales" de la violencia doméstica y "testigos afectados" por la violencia de que son viclimas sus madres desarrollan conductas confliclivas. Tanto los nifos como las mujeres afectados por la violencia no saben o no pueden defenderse ni reaccionar ante ella para terminar con dicha situación. Pero la violenoia no afecta sólo a las victimas, sino que deshumaniza y aisla también a los hombres agresores al interior de su Iamilia.

A nivel social se establece una espiral de violencia y discriminación, pues las victimas llevan en su memoria guardadas las imágenes y los eleclos destructivos de la violencia que los convierte en reproductores activos o pasivos de la misma. Además, al mantener una situación discriminaloria contra la mujer a través de la violencia, la sociedad des- 
perdicia o se niega el aporte de al menos la mitad de sus miembros en los aspectos económico, social, político, cientifico y cultural, necesarios para el desarrollo de la misma.

La permanencia de la violencia exige del Eslado la asignación de recursos para la atención curativa, correctiva y centrada en la víctima que, además de mayores que los requeridos para realizar medidas de carácter preventivo, no son sulicientemente eficaces.

Pero a pesar de los efectos de la realización de actos violentos, éstos no son considerados por muchos como un problema debido a su carácter cotidiano, a algunas actitudes latalistas y a su complejidad (Franco, 1991).

El que la violencia contra la mujer se haya convertido en cotidiana impide que sea cuestionada por algunas mujeres y que sea considerada como un objeto de investigación y de denuncia social. El que se la considera como inherente al ser humano y por ello inevitable explica actitudes latalislas que llevan a la resignación e inacción por parte de las mujeres, la sociedad y el Estado.

Al ser un problema complejo por la mulliplicidad de lactores y variantes, asl como por su relación con el poder y porque exige acciones en múlliples ámbitos de la vida sin pretender oblener efectos inmediatos se la hace un dilicil objeto de la planificación y del linanciamiento.

\section{SITUACION EN EL SALVADOR}

\subsection{Area de la salud.}

\subsubsection{Sector Gubernamental.}

En general, el sector gubernamental atiende casos de agresión física y violación sexual; tal vez porque en estos tipos de violencia contra la mujer sus efectos inmediatos son más visibles o porque son los que Iradicionalmente se consideran hechos violentos y que, por lo tanto, sólo en estos casos acude la víctima en busca de atención y porque quizá para ellas, sólo en eslos casos corre peligro su vida.

En general, y dado el tipo de violencia/agresión que por ahora atiende el Sector Gubernamental, se pueden distinguir dos ramas en el Area de Salud en las que se brinda atención a las víctimas (mujeres, niñas, nifios). Una es la médica y olra la salud mental que liene poco peso en relación a la alención médica tradicional en general y a pesar de que cerca del $80 \%$ de consultas en el área de salud mental son de mujeres; 
y de que la población femenina cuenta con más posibilidades de enfermarse mentalmenle, ya que además de estar expuesta a las mismas condiciones que hacen entermar a los hombres, están expuestas a otras ya muy propias de su género tales como embarazos no deseados, madres adolescentes, abortos inducidos, violencia intralamiliar, agresión sexual. Conlando además con que la mayoría de las mujeres que llegan a consulta de salud mental son amas de casa. Hay que agregar que el servicio institucional de medicina liende a adminislrar medicamentos $y$ nada más; incluso podriamos decir que no se diferencia en nada de los procedimientos $y$ atenciones en otros casos que lienen lugar en los diversos hospitales del país.

Las dificultades para alender a la mujer victima de la violencia a partir de los servicios existentes se refieren a los recursos tanto humanos como materiales con que se cuenta (o no se cuenta). $Y$ pueden explicarse debido a que la preocupación por el problema de las mujeres además de reciente (en el país) es aún insuliciente.

Existen iniciativas impulsadas por la Secretaría Nacional de la Familia y concreladas en las Clínicas de alención inlegral a la agresión sexual que se apoyan en algunos hospitales del sistema nacional y que atienden fundamentalmente los casos de agresión sexual en mujeres y de maltratos en nifios y nifias. Con lo cual la alención directa a la mujer víctima de la violencia se concentra en un tipo de violencia: la violación, que además es reducida a los casos en que la relación sexual ha producido "ruplura de algo" por la forma de penetración. Se dejan fuera no sólo otras formas de agresión sexual sino otras formas de violencia.

Todo lo anterior explicaria el que no siempre se cuente con el personal de planta necesario, leniendo que recurrir a profesionales "ad honorem" que cumplen asi con el requisito de prestar "el servicio social" o bien a profesionales de otras instituciones para suplir dicha falta.

De modo que el personal además de no ser estable y requerir por ello de una capacilación periódica para mejorar su percepción del problema y su actilud ante la mujer, se encuentra con una sobrecarga de Irabajo que le dificulta un verdadero seguimiento a cada caso.

En cuanto a recursos materiales en algunos casos no se cuenta con un local propio y adecuado que responda a las necesidades de espacio, equipo médico y privacidad requeridos.

Considerando ahora el punto de vista de la mujer que hace uso de dichos servicios, ésla tiene que repetir el proceso de examen físico y toma de declaración en más de una ocasión con el consiguienle sufrimiento y la vergüenza al verse obligada a recordarlo y hacerlo público. 
Además, su atención tanto médica como psiquiátrica suele retrasarse en cuanto a la hora o a la lecha de la cila. Estos elemenlos pueden explicar no sólo el que las mujeres no demanden los servicios y el que quienes hacen uso de ellos dejen de acudir al seguimiento ofrecido.

\subsubsection{Sector no-gubernamental.}

Mientras el seclor gubernamental se ocupa, sobre todo, de la atención médica tradicional, el sector no-gubernamental se ocupa más de la atención psicológica. Probablemente por lo cosloso y complicado de montar y mantener una clínica médica y también por contar con menor cobertura y menos recursos. Aunque brinden atención médica y de salud mental igual que el sector gubernamental, el éntasis está en esta úllima. Además tralan de incorporar una visión de género en ambas áreas. Asi es común encontrar en este sector charlas de orientación, de autoestima, organización de grupos de rellexión. Mediante talleres en las propias comunidades se dan charlas sobre la violencia intratamiliar o "ejes de sensibilidad". Este lipo de atención asume pues rasgos preventivos-comunitarios. Por eso también es Irecuente enconirar terapia psicosocial. Por lo mismo, la atención es más personalizada y cubre una mayor variedad de lipos de violencia alendidos. Aunque, en la parte asistencial los servicios prestados son muy semejantes a los que se dan en las clínicas médicas y psicológicas convencionales del Estado.

La Coordinadora Nacional de la Mujer Salvadorefa (CONAMUS) es quizás la única de las instituciones gubemamentales que cuenta con una clínica para brindar alención médica a los casos de agresión sexual e intrafamiliar. El tratamiento va acompafado también del tratamiento psicológico hacia la mujer violenlada. Sin embargo, la atención psicológica no se restringe a ellas y olrece también otro tipo de consullas relacionadas a otros transtornos mentales de las mujeres, probablemente producto lambién de una situación permanente de violencia contra ellas.

Las instituciones del sector no gubernamental de las que se obtuvo información parecen no tener problemas para ofrecer asistencia médica a las mujeres víctimas de la violencia. Las mayores dificultades se alribuyen entonces a faclores culturales, algunos de los cuales interfieren con la terapia psicológica ofrecida. Las mujeres que siendo viclimas de la violencia familiar buscan asistencia se encuentran en una situación dificil para llevar adelante la terapia y lograr recuperarse porque deben permanecer en el hogar junto al companero agresor sin que exista la disposición de colaborar por parte del compañero. Además como las mujeres se encuentran ligadas afectivamente al agresor o presionadas 
socialmente a mantener dicho vínculo dificilmente pueden aceptar la separación como posible solución.

\subsection{Area Legal.}

\subsubsection{Sector gubernamental.}

El sector gubernamental salvadorefio presta atención a los problemas de violencia contra la mujer a través de las instituciones encargadas de administrar la justicia: el Organo Judicial y sus inslancias pertinenles como los juzgados de primera inslancia y el Instiluto de Medicina Legal Dr. Roberto Maslerrer (IML), y las instituciones de la Fiscalía General de la República (FGR) y la Procuraduria General de la República (PGR). Se cuenta además con el proyecto de las Oficinas de Defensoría de la Mujer, que están siendo organizadas por la Secretaría Nacional de la Familia.

Esle seclor aliende básicamente los casos de agresión sexual y de agresión física no sexual. Aunque se sefiala que la Procuraduría atiende, en cambio, otro tipo de problemas tales como los casos de abandono, reclamos por cuola alimenlicia que la mujer hace al compafiero para los hijos de la pareja, elc. Problemas que si bien son de violencia no son necesariamente de agresión.

La agresión sexual se encuentra bien definida y clasificada por el código penal bajo la categoria de "delitos contra el pudor y la libertad sexual". Clasificación que se subdivide en violación sexual en el caso de que la agresión se consume con un acceso carnal, y en abusos deshoneslos, en el caso que la agresión no haya culminado con el acceso carnal, o el acceso no sea carnal sino con algún otro objeto. Esto último puede tener como agresor tanto a una mujer como a un hombre (dado que no existe penetración camal). En cambio la violación sólo puede tener como hechor a un hombre. Bajo el conceplo de abusos deshoneslos se colocarian también aquellos casos en que la violación no fue totalmente probada.

A diferencia de los delitos contra el pudor y la libertad sexual, las agresiones no se encuentran tipificadas más que por el lipo de lesión que producen. No se hacen distinciones entre la agresión doméstica, la riña callejera, los accidenles de tránsito $u$ otros. Las penas varían según el lipo de lesión sin considerar el tipo de agresión a que se refiere.

En cuanlo a dificultades se refiere, en primer lugar la legislación salvadoreña aborda el problema de la violencia contra la mujer de una forma general. La mujer es enlonces una persona lesionada ante lo cual 
no se hace distinción de sexo. A pesar que los delitos contra el pudor y las agresiones domésticas (fuera de los ninos) tiene como principal victima a las mujeres. $Y$ a pesar que en la agresión doméstica por la propia naluraleza de los participantes no se pueden imponer las mismas sanciones que para otras agresiones físicas.

La lipificación en grandes delitos agrupa lesiones tan distintas como la rifa callejera, robos, asaltos y hasta accidentes de tránsito. Deja además, una serie de vacíos que resultan en que algunos problemas como el asedio sexual en el trabajo y el maltrato psicológico son considerados illcitos más no constituyen delitos. Además que son cuestiones dificiles de probar por la ausencia de lestigos o peritajes del IML aunque ésle tenga psiquiatras y psicólogos trabajando allá.

Los procedimientos llevan también varias dificultades para là presentación de las pruebas. Sobre todo por los requerimientos que se deben llenar para dictaminar la agresión sexual y por la presentación de lesligos para casos que por ser delitos "privados" no se cometen frente a tesligos.

Por otro lado, la coordinación establecida entre la atención médica y la alención legal como iniciativa de la SNF liene limitaciones al respecto, ya que si la agredida acude primero a la instancia legal no recibe atención médica y psicológica inmediala ya que el IML no cuenta con recursos para ello y no pueden adminisırar un tratamiento de prevención de un embarazo bajo estas circunslancias o de prevención contra enlermedades de transmisión sexual (para el caso de la agresión sexual). Y si la mujer acude primero a las clínicas luego se le hace díícil probar el delito (ya que el médico forense no siempre llega a la clínica) o se duplicarán los inlerrogatorios, agravando el cansancio y la vergüenza de la víctima.

Aunque se reconoce que hay vacios signiticativos en la legislación para cubrir el problema, lo más difícil parecen ser las limilaciones de lipo cultural en tanto que la violencia (agresión) contra la mujer sigue siendo considerada un problema secundario o de carácter "privado" con lo que se quiere decir que es de la exclusiva incumbencia de la agredida o de la lamilia que sufre la agresión del esposo/padre. Esto es asi tanto para el personal encargado de recibir las denuncias y procesar como para las mismas agredidas que o no denuncian los hechos o desisten de continuar con el proceso. Aqui específicamente influyen los sentimientos de vergüenza, baja autoestima, la imporlancia de cuidar el "buen nombre" y la supuesta "unidad familiar", así como la dependencia emocional y/o económica de la víclima hacia el agresor. 


\subsubsection{Sector no gubernamental.}

Dentro del sector no gubernamental se cuenta con algunas organizaciones que prestan servicios de asistencia o asesoria legal como el Institulo de la Mujer (IMU), el Centro de Estudios de la Mujer (CEMUJER) y la CONAMUS. EI IMU cuenta con una unidad especial para atender los problemas de asislencia legal: el Centro de Alención Legal para la Mujer Salvadorena (CALMUS). Y CONAMUS presta los servicios a través de su clínica.

Eslos centros están en principio, abiertos a todo tipo de denuncias de agresiones contra la mujer que puedan seguir un proceso judicial. Sin embargo alienden en su mayoría procesos de violación sexual y maltralo doméstico, a excepción de CALMUS que atiende otros tipos de situaciones como reclamos por la cuola alimenticia y además una serie de procesos judiciales que no necesariamente son de violencia o de agresión, tales como: divorcios, traspaso de propiedades, trámiles migralorios, elc. CEMUJER, por olro lado, en tanto que no brinda más que asesoría, dice brindarla para casos de olras agresiones como la discriminación laboral por ejemplo.

En general eslas organizaciones prestan servicios de asesoría y/o asistencia legal para las mujeres violenladas. Su trabajo es tundamentalmente el de servir de puente entre la agredida y los servicios tradicionales que presla la administración de justicia gubemamental, asesorando a la mujer sobre cuáles son los servicios que puede solicitar, cuáles son las leyes que le inleresa conocer para alender su problemática y cómo puede hacer uso de ellas. $Y$ en algunos casos preslando los servicios de una abogada.

Las organizaciones consultadas reconocen dificultades relacionadas con la ley y con la mujer. Con la ley explícitamente se dice que la legislación muy poco cuida los intereses de las mujeres y por lo mismo consultan leyes "retrógradas" que no ofrecen ninguna solución para los casos de agresión que ellas sufren. En cuanto a la mujer, ellos sefialan que hay dificultad en las agredidas para realizar una acción radical y delinitiva como la de dejar al companero que la maltrata y vive en estado de dependencia emocional y económica con respecto a él. Aquí intervienen problemas de baja auloestima y el miedo a enfrentarse sola en una situación diferenle y sobre la cual cree no tener conlrol.

\section{CONCLUSIONES Y RECOMENDACIONES.}

\section{Conclusiones.}

1. Considerando la magnitud del problema de la violencia contra las 
mujeres, la camtidad de unidades de atención no dan la cobertura suficiente, especialmente por estar concentrados en el área de San Salvador, si se toma en cuenta que este fenómeno ocurre a lo largo y ancho del pals. Además, se puede diferenciar cierta "especialización" en el tipo de unidades de atención por sector. Asl, la parte psicológica es mayormente cubierta por organizaciones no-gubernamemlales en tanto que la alención médica es cubierta mayormente por el sector gubernamental.

2. Independientemente de si se trala del sector gubernamental como del no-gubernamental, la alención y los servicios están orientados básicamemle a las victimas de agresión llsica o sexual, incluyendo las áreas médica y psicológica-psiquiátrica. En ambos casos se estaría Iratando de implementar un tratamiento que considere una visión de género. Mayor claridad en este punto lo muestra el sector no-gubernamental y ya puede vislumbrarse un interés por la parte preventiva a este problema. En este sentido es como deben entenderse "las jornadas de reflexion-sensibilización" y el recurso a las terapias psicosociales. Por esta misma razón este problema está comenzando a verse no como algo individual ni sólo asistencialista. Cada vez está ganando terreno la visión comunitaria del problema.

3. Las dificultades en el área de salud que lienen las unidades que atienden esle tipo de problemas pueden clasificarse en dos tipos: de recursos maleriales y humanos y de utilización electiva por las usuarias. Se necesitan instalaciones, equipo, financiamiento y personal capacilado, pero también los Iratamienlos deben replantearse para que éste no sea motivo para que las usuarias los suspendan o les rehuyan.No se debe pasar por allo también los problemas de cobertura nacional y los problemas de uso real por parte de las victimas.

4. Los tipos de violencia que se alienden están más bien releridos a la agresión fisica y a la agresión sexual. Así dejan fuera una buena cantidad de situaciones violentas. Cuestiones que incluso son reconocidas como objelo de atención, en la práctica exislen Irabas para su atención lales como que no son reconocidas como delitos o que no se considera la naturaleza particular de los delitos y agresiones que tienen como víctima a la mujer. O que en la práctica también, sencillamente no se atienden ni se buscan atender. El conceplo de violencia que se maneja es pues, bien pobre en tanto que resulta en una atención limitada para unos tipos de agresión limilados lambién.

5. La atención olrecida a las víctimas de agresiones físicas y de agresiones sexuales está limitada en lanlo que los procedimienlos son excesivamente burocráticos e implican unos procesos largos, cansados y lediosos; deben ser examinadas por varios médicos o personas; dar 
declaraciones una y otra vez, con dificultades para ser atendidas en su salud y los requerimientos legales al momento del incidente (ambas necesidades prioritarias para los momentos inmediatos al hecho). Procedimientos que exigen una gran cantidad de requisitos para ser procesados tales como los requisitos que deben tener para un caso de violación es que debe presentar muestras dę violencia o agresión fisica constante y de no llenarla se hace suponer que ella consintio. O el hecho de tener que presentar testigos cuando por la naluraleza de estos delitos esos tesligos no existen. Eslos procedimientos que además tratan de igual forma a los que se cometen sin distinción de sexo, con sanciones iguales a los demás; siendo que una persona y mucho menos una mujer no va a denunciar y a pedir de igual manera una pena si se trata de un desconocido o de su parienle y que los efectos sobre la víctima no son iguales en ambos casos. A pesar de estar considerados por ley (caso de la agresión sexual) o de hecho (caso de agresión doméslica) como delitos privados, que incumben sólo a la lamilia y la victima y no a la sociedad entera. Según esta manera de ver el problema, un marido que golpea a su mujer no serla una amenaza para la sociedad, entonces, ¿por qué debe guardar prisión al igual que un ladrón?, ¿cómo consigue la mujer el dinero que ésle le proporcionaba para mantemer a los hijos?, ¿que hace ella con el sentimiento de culpa de haber encerrado al padre de sus hijos?, más bien, ¿no habrán otras formas de abordar esle problema de la agresión doméstica?.

Por otro lado, la coordinación enire la Secrelaría Nacional de la Familia y los Juzgados se muestra deficienle en tanto que desde la primera no es posible hacer simulláneamente la denuncia y desde la segunda no es posible obtener la atención médica. Los médicos forenses y los fiscales no siempre van a las clínicas a reconocer a la viclima y a levantar actas sobre el caso.

6. Sin embargo, se hace notar algunos de los logros tales como la instalación de las clínicas de la SNF que con todo y sus deticiencias es muestra de preocupación hacia ese problema. Es imporlante el hecho de que el IML esté llevando datos estadislicos sobre los casos de violación registrados por ellos, ya que con su difusión se busca sensibilizar de alguna manera a pesar de no mostrarse aún como un delito contra mujeres. Y además, porque los Juzgados no llevan datos estadisticos sobre el asunto y por ello mismo no puede apreciarse la magnitud de los aclos denunciados.

Es interesante ver como algunas ONG han retomado el problema para ser atendidos por ellos. Esla es una necesidad que las ONG pretenden cubrir. Sin embargo para ellas esto es muy dificil ya que no 
cuentan con la red nacional con que si cuenta el Estado.

\section{Recomendaciones.}

1. Por la magnilud e incidencia de la violencia conlra la mujer deben realizarse esfuerzos por ampliar su conceplualización y tipificación para que sea considerado un problema de salud pública.

2. El que la legislación no establezca diferencias si la victima de la violencia es una mujer, justifica la necesidad de que, en algunos casos, la revisión de la dicha legislación indique la creación de nuevos delitos y la modificación de los procedimientos y las sanciones. Con ello se lograría incorporar en dichas instancias las necesidades y el punlo de vista de la mujer.

3. Deben revisarse las actuales sanciones y evaluar la posibilidad y conveniencia de no reducir las penas carcelarias o días-multa, sino acompafiarlas o sustituirlas por medidas que busquen la rehabilitación del agresor, tomando en cuenta que el agresor suele ser un conocido o incluso un familiar de la víctima.

4. Es necesario difundir los derechos de la mujer, la legislación que la ampara y los lugares que puede acudir a recibir asistencia para evitar que las demandas no sean presentadas o sean retiradas sin haberse concluído el proceso.

5. Hay que continuar realizando estuerzos por establecer coordinación entre la asistencia legal y en salud para olrecer a las mujeres una asistencia realmente integral. Con ello se evitarían la duplicación de esfuerzos, la burocratización de algunos trámites y el sulrimiento de la victima y la realización de esluerzos aislados y secloriales.

6. Crear conciencia de que la violencia contra la mujer es una situación que se ha mantenido invisible al ser considerada natural, tanlo entre las mujeres como entre los agentes sociales que tienen comtacto con las víctimas de la violencia en distintos momentos del proceso (educadores, personal de salud, agentes sociales, abogados, psicólogos, etc).

7. Orientar esluerzos de prevención que apoyen la familia y los roles considerados femeninos, como unidad primaria de prevención. La mujer debe ser vista como educadora y transmisora de conductas prevenlivas capaces de romper el circulo de la violencia.

8. Evitar el aislamiento social de la mujer víclima de la violencia. Favoreciendo los grupos en que participan o puedan participar mujeres par que cumplan un rol de apoyo y entrega de inlormación a las mismas. 


\section{Relerenclas blbllográflcas.}

Cañas, Mercedes (1990). "Mujeres y violencia en El Salvador, un problema más allá de la guerra". Palabra de Mujer No.1 (pp.4-9). San Salvador: Coordinadora Nacional de la Mujer Salvadoreña.

Franco A., Saúl (1991). "La violencia en los tiempos del cólera". Ponencia presentada al Segundo Taller Latinoamericano de Medicina Social. Caracas: folocopia.

Martín-Baró, lgnacio (1988). "Violencia y agresión social" en Acción e ldeologla, Psicología social desde Centro América. San Salvador: UCA editores. 